\title{
Fructose Malabsorption Influences Chronic and Recurrent Infectious Diseases, Dyspepsia and Heartburn
}

\author{
Yali Sui $^{1, *}$, Gordana Djuras ${ }^{2}$ and Gerhard M. Kostner ${ }^{1}$ \\ ${ }^{I}$ Department of Biochemistry and Molecular Biology of the Medical University of Graz, Austria \\ ${ }^{2} J o a n n e u m$ Research, Leonhardstrasse 59, Graz, Austria
}

\begin{abstract}
Background: Fructose malabsorption has been associated with irritable bowel syndrome (IBS), but its impact on infections of the respiratory and urogenital tracts, inflammation of the skin, as well as dyspepsia and heartburn, has not been studied.

Methods: Fructose absorptions of 62 outpatients with clinical signs of IBS were monitored by a fructose- $\mathrm{H}_{2}$ - breath test. Additionally, the urinary fructose concentration was monitored during a 2-hour test period. Patients were asked to answer a questionnaire to evaluate their discomfort and to diagnose multiple chronic or recurrent diseases. Patients with manifested fructose malabsorption were put on a reduced fructose diet for up to 3 years. At the end of follow-up, patients were called in again for evaluatation of their dietary compliance and possible development of persistent complaints.

Results: Patients with fructose malabsorption had higher urinary fructose concentrations during the fructose tolerance tests than did normal fructose absorbers $(46.7 \pm 36.4 \mathrm{mg} / \mathrm{dl} v s .18 .7 \pm 10.1 \mathrm{mg} / \mathrm{dl} ; \mathrm{p}<0.01)$. Chronic or recurrent infections of respiratory and the urogenital tracts, inflammation of the skin, as well as dyspepsia and heartburn were more than twice as high in fructose malabsorbers than in normal absorbers (78.1\% vs. 36.7\%). The risk of chronic and recurrent illnesses was higher in the group of fructose malabsorption $(\mathrm{p}=0.002)$. A fructose-restricted diet significantly reduced the vulnerability to various forms of chronic or recurrent diseases.
\end{abstract}

Conclusions: Chronic and recurrent infections of respiratory and urogenital tracts, inflammation of the skin, dyspepsia and heartburn correlate with fructose malabsorption. A dietary fructose reduction was effective in reducing these illnesses.

Keywords: $\mathrm{H}_{2}$ - breath test, fructose malabsorption, respiratory tract, urogenital tract, dyspepsia, heartburn.

\section{INTRODUCTION}

To date, fourteen members of the mammalian glucose transporter (GLUT) have been identified. For the ingestion of fructose GLUT-5 is of major importance [1-6]. The GLUT-5 mRNA is mainly expressed in the small intestine but can also be found in skeletal muscles, the kidney, adipose tissues, spermatozoa, brain and tumor tissues [1-15]. Mutations and polymorphisms of GLUT-5 are hallmarks of fructose malabsorption [1] that lead to imperfect fructose absorption in the small intestine. Excess fructose in turn enters the large intestine, where microorganisms of the colonic flora ferment it. This causes inflammation, abdominal pain, bloating and diarrhea. For a clinical diagnosis the wellestablished hydrogen $\left(\mathrm{H}_{2}\right)$ breath test is currently the method of choice. Fructose malabsorption is very common: up to $30 \%$ of the populations of Western and African countries are affected. The prevalence in Asia is much lower with up to $10 \%$ of the population affected [16]. The Western diet is very rich in fructose: foods containing large amounts of fructose include corn syrup, honey, sucrose, apples, pears, raisins, chestnuts, mangos, oranges and many other fruits.

*Address correspondence to this author at the Medical University of Graz, Harrachgasse 21, A-8010 Graz, Austria; Tel: 0043-3168-33509; Fax: 0043-3168-33509; E-mail: yali@gmx.at
Estimates of the average daily intake of fructose in adolescents and adults in the US range from 15 to $54 \mathrm{~g} / \mathrm{d}$, with a mean of $37 \mathrm{~g} / \mathrm{d}$ [17]. According to statistics 12 to 18 year old males have the highest fructose intake $(72.8 \mathrm{~g} / \mathrm{d})$ [18]. Urinary extrinsic sugar excretion correlates significantly with the dietary uptake of fructose [19].

Many studies have established the correlation of fructose malabsorption with irritable bowel syndrome (IBS). However, a possible correlation of fructose malabsorption with other chronic illnesses has not been studied so far. We have therefore addressed this issue in the present paper and show, that fructose malabsorption is significantly associated with infections of the upper and the lower respiratory tract, the skin, the urogenital tract, as well as with dyspepsia and heartburn. A fructose-restriected diet significantly alleviates these complaints.

\section{METHODS}

One hundred and six adult outpatients were enrolled for this study between May 2007 and September 2010. Exclusion criteria were diabetes mellitus, liver or kidney disease, hereditary fructose intolerance, lactose intolerance and histamine intolerance. Twenty-four patients were noncompliant and were thus excluded from further analysis. Sixteen patients were excluded because of lactose intolerance 
and four patients were excluded because of histamine intolerance.

The remaining 62 participants were aged between 21 and 70 years, 48 of them being female and 14 male. All participants have given their consent. We also made sure that the subjects had not taken antibiotics and had not undergone a colonoscopy 2 months previous to the investigation.

\section{Fructose- $\mathrm{H}_{2}$ Breathe Test and Collection of Urine}

On the day of examination the subjects were asked to avoid any food rich in fructose such as corn syrup, honey, fruits, dairy products or vegetables known to cause flatulence (such as legumes, cabbage, onions, garlic or potatoes). On the eve of submission to the fructose tolerance test patients were asked to refrain from meals after $7 \mathrm{pm}$. Furthermore the subjects did not have any breakfast on the day of testing; thus they fasted for a minimum of 12 hours. Before undergoing the $\mathrm{H}_{2}$ breath test, urine samples were collected to measure the initial fructose levels. The first breath sample served as a zero control and was taken before the fructose load. Since the fasting $\mathrm{H}_{2}$ levels should be $<10$ parts per million [20], the testing of participants whose $\mathrm{H}_{2}$ in breath exceeded this value was postponed for another day. Subjects were then given $50 \mathrm{~g}$ of fructose, dissolved in $400 \mathrm{ml}$ of tap water. Afterwards the $\mathrm{H}_{2}$ in breath was monitored every 15 minutes during the first hour and at 30 minutes intervals during the second hour. For the detection of $\mathrm{H}_{2}$ in breath a portable device (Gastrolyzer, Bedfont Scientific Ltd, Station Road Harrietsham Maidstone Kent ME17 1JA, England) was used. In addition to that urine was collected every 30 minutes for a period of two hours. The amounts of $\mathrm{H}_{2}$ exhalation after the fructose load were recorded and the differences to the initial levels were calculated. At the end of the two-hour $\mathrm{H}_{2}$ breath testing period, subjects were asked to report any symptoms like bloating, diarrhea, abdominal pain, or headache for additional documentation.

\section{Definition of an Abnormal $\mathrm{H}_{2}$ Breath Test}

An abnormal fructose breath test was defined as an elevation of $\mathrm{H}_{2}$ in the breath of $>20$ parts per million (ppm) in the first 3 hours of testing [20]. Patients exhibiting abnormal fructose breath tests were admitted to a reduced fructose-diet scheme.

\section{Urine Analysis}

Urine collection started simultaneously with the fructose tolerance $\mathrm{H}_{2}$ breath test. Urine samples were collected at the beginning and then every 30 minutes for two hours and were temporarily stored at $4^{\circ} \mathrm{C}$ for maximally $4 \mathrm{hrs} .4 \mathrm{ml}$ urine samples were centrifuged for 10 minutes at $4000 \mathrm{rpm}$ and the supernatant was stored at $-20^{\circ} \mathrm{C}$ for further assays. Urine samples with detectable blood contaminations were deproteinized by adding a solution containing $0.33 \mathrm{~mol} / \mathrm{l}$ of perchloric acid at a ratio of 1:10, the mixture was stirred vigorously and centrifuged before fructose was analyzed.

Urinary fructose assay: For the enzymatic measurement of fructose in urine a spectrophoretic method using a Riele Photometer (PM750L, Germany) was applied. Enzymatic assays contained hexokinase and phosphoglucose isomerase
(D-Fructose and D-Glucose Kit/ Megazyme International Ireland Ltd., Bray Business Park, Bray, Co. Wicklow, Ireland).

\section{Monitoring of Chronic Illnesses}

Diagnoses obtained from specialists were divided into five groups: 1. Infection of the upper and the lower respiratory tract; 2 . Inflammation of the skin; 3 . Recurrent urogenital infection; 4. Dyspepsia and 5. Heartburn. The 25 diagnosed fructose malabsorbers suffering from chronic or recurrent diseases were called in at various periods of time and received a questionnaire for the assessment of their current symptoms. These symptoms were graded according to the following scale: no complaints, no antibiotics or no proton-pump inhibitor; rare complaints, rare antibiotics or proton-pump inhibitor; unstable, but better than previously; unchanged; deterioration. Additionally, patients that reported their usual frequency of fructose consumption were divided into 6 categories according to their compliance to the recommended low-fructose diet: Category I: 90-100\% compliant; category II: $80-89 \%$ compliant; category III: 70 $79 \%$ compliant; category IV: $60-69 \%$ compliant; category V: $40-50 \%$ compliant and category VI: not compliant at all.

\section{Statistics}

The data of this study were analyzed using statistical software R [21], version 2.8.0. A Shapiro-Wilk test [22] was used to test for normal distribution of the parameters. The nonparametric Mann-Whitney U-test [22] was applied to determine if a significant difference between two independent groups existed. For determining the statistical dependence between two parameters the Spearman's rank correlation coefficient was calculated [23]. Comparisons of categorical data were performed by using the Fisher exact test [23]. $\mathrm{p}<0.05$ was considered as significant.

\section{RESULTS}

Of 62 participants in this study, thirty-two (mean age of $41.5 \pm 10.6$ years) exhibited abnormal breath tests with elevated $\mathrm{H}_{2}$ concentrations of $>20 \mathrm{ppm}$ over basal fasting $\mathrm{H}_{2}$ values and hence were classified as fructose malabsorbers. The remaining 30 participants (23 females and 7 males aged $43.4 \pm 12.6$ years) were classified as normal fructose absorbers.

The mean fructose levels measured in urine over a period of $120 \mathrm{~min}$ were significantly higher in fructose malabsorbers than in normal absorbers $(p<0.01)$ (Fig. 1). A peak of urinary fructose concentrations in malabsorbers was observed after $60 \mathrm{~min}$. In the breath test of the fructose malabsorbers the peak $\mathrm{H}_{2}$ level was reached after $90 \mathrm{~min}$ (Fig. 2). As shown in Fig. (3) the mean urinary fructose concentrations did not correlate with age and hydrogen $\left(\mathrm{H}_{2}\right)$ concentrations.

Twenty-five of the 32 fructose malabsorbers $(=78.1 \%)$ and eleven of the 30 normal fructose absorbers $(=36.7 \%)$ suffered from chronic and recurrent diseases. The risk of chronic and recurrent diseases was 6.17 times higher in the group of fructose malabsorbers than in the fructose digesters as calculated by the Fisher's exact test $(p=0.002)$. The 


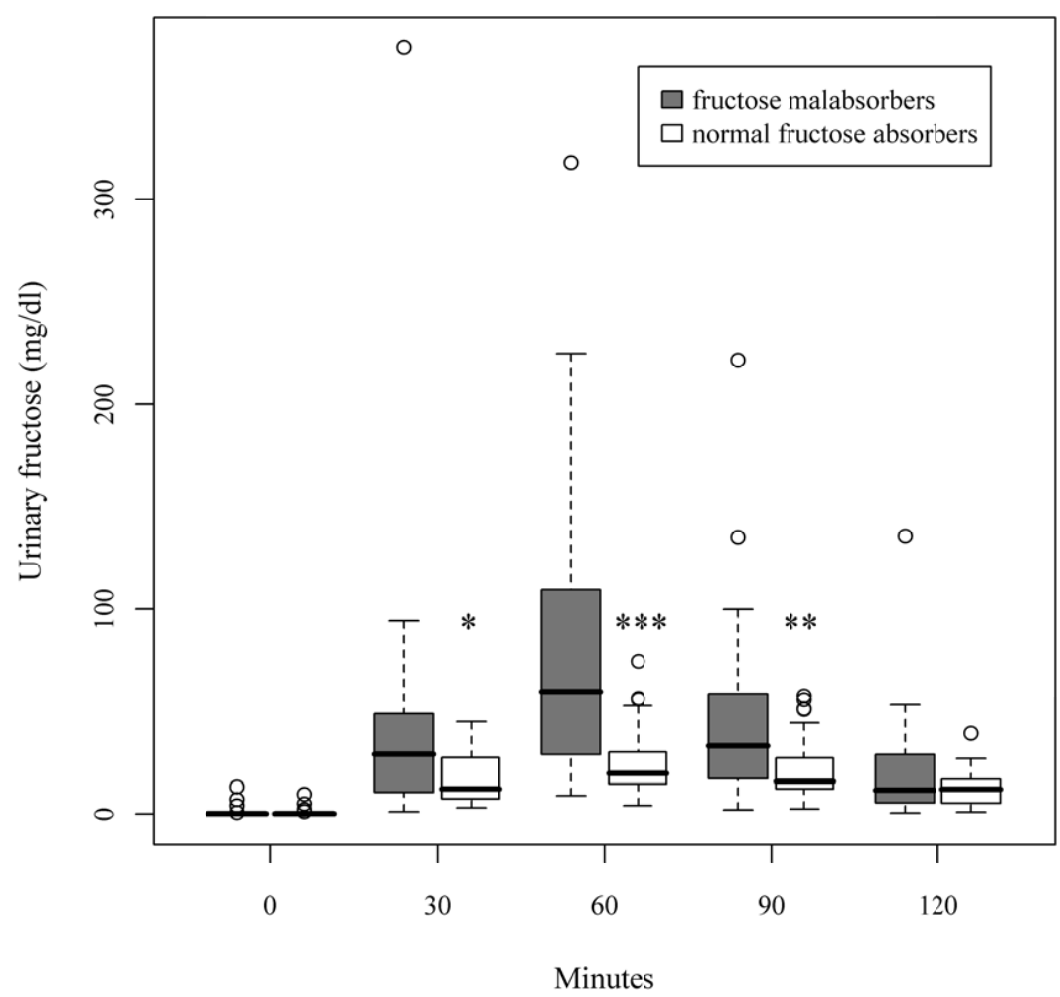

Fig. (1). Urinary fructose levels recorded during the $\mathrm{H}_{2}$ breath test after intake of $50 \mathrm{~g}$ fructose. Data from 62 probands $(32$ fructose malabsorbers) were recorded between 0 and 120 minutes after fructose intake. $*: \mathrm{p}<0.05 ; * *: \mathrm{p}<0.01 ; * * * \mathrm{p}<0.001$.

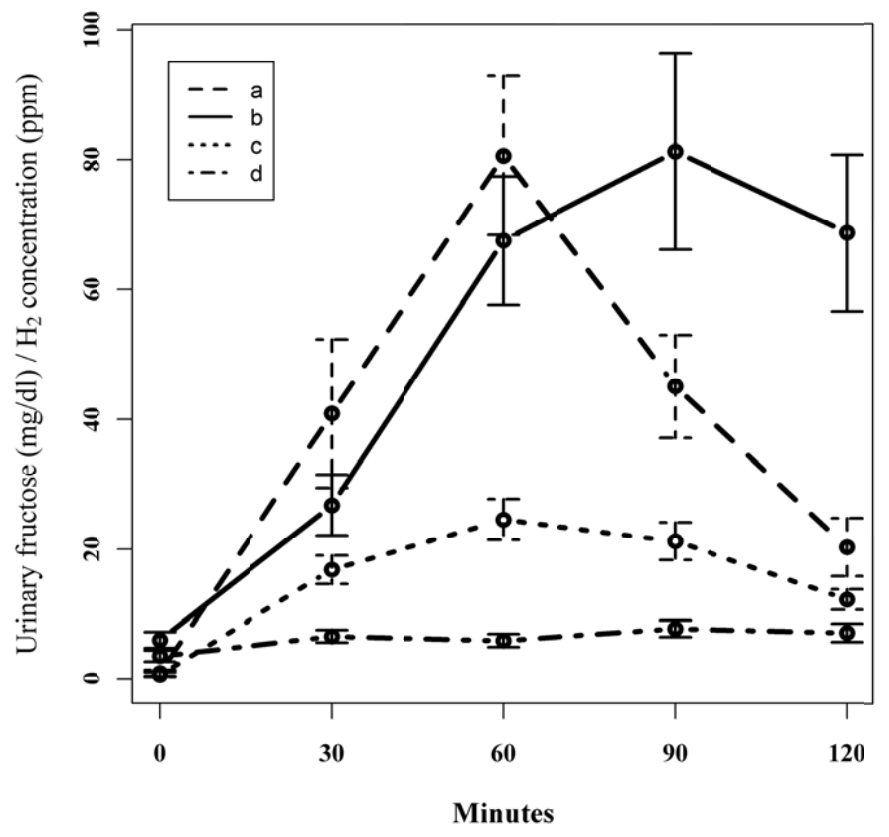

Fig. (2). Mean urinary fructose levels and mean $\mathrm{H}_{2}$ concentration of 62 participants during $\mathrm{H}_{2}$ breath test. a : urinary fructose in fructose malabsorption; b : $\mathrm{H}_{2}$ concentration in fructose malabsorption; $\mathbf{c}:$ urinary fructose in normal fructose absorption; $\mathbf{d}: \mathrm{H}_{2}$ concentration in normal fructose absorption. 

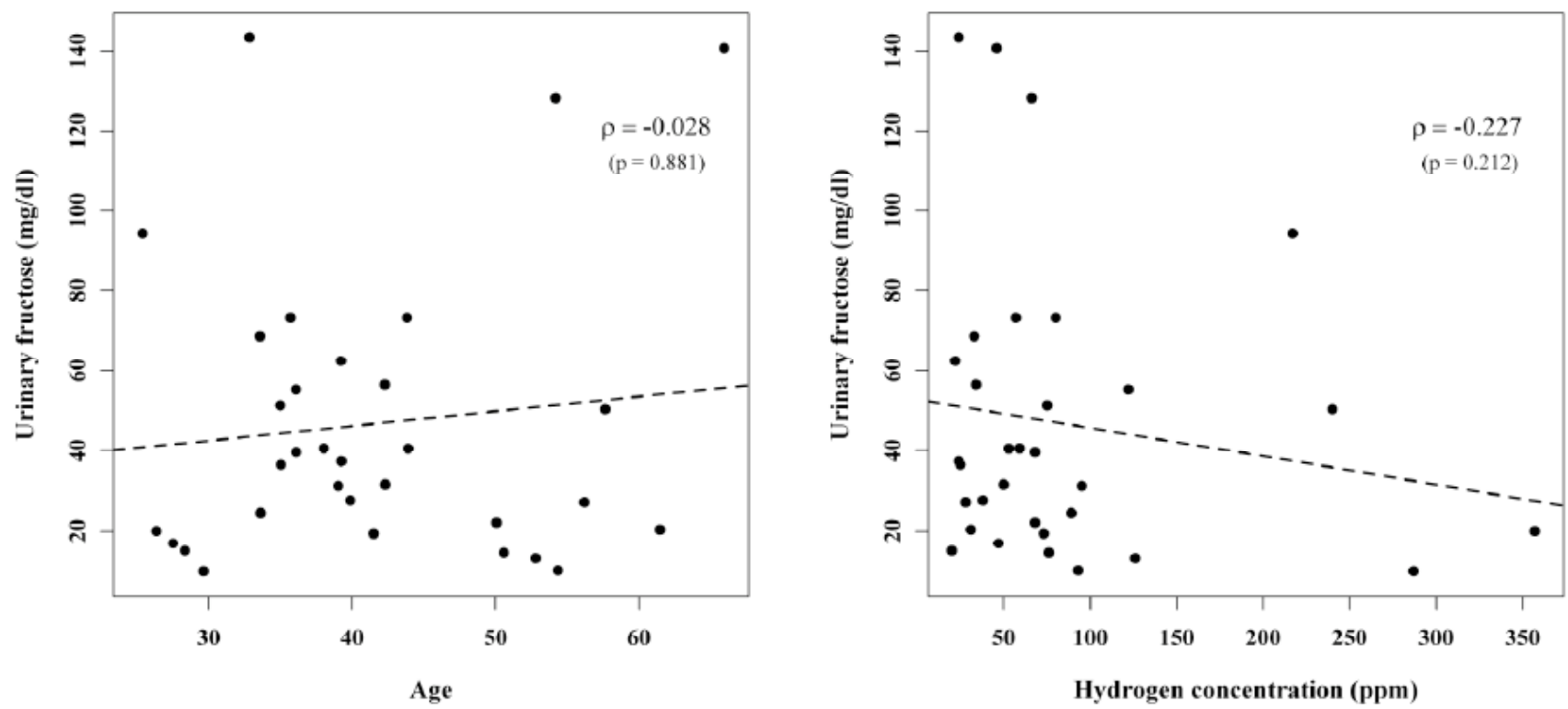

Fig. (3). Correlation of mean urinary fructose levels of the 32 malabsorbers with age (left) and hydrogen concentrations (right).

Table 1. Category and Frequency of 38 Chronic and Recurrent Illnesses Observed in 25 Fructose Malabsorbers

\begin{tabular}{|c|c|c|c|}
\hline & Bacterial Diseases & Other Illnesses & Total \\
\hline Respiratory infections (Group 1) & $12(31.6 \%)$ & $1(2.6 \%)$ & $13(34.2 \%)$ \\
\hline Heartburn (Group 3) & & $4(10.5 \%)$ & $4(10.5 \%)$ \\
\hline Recurrent urogenital infections (Group 4) & $5(13.2 \%)$ & & $5(13.2 \%)$ \\
\hline
\end{tabular}

*) The number of fructose malabsorbers was 25 , yet some oft them had more than one chronic illness. Thus the sum of observed diseases in the last column is 38 and not 25 .

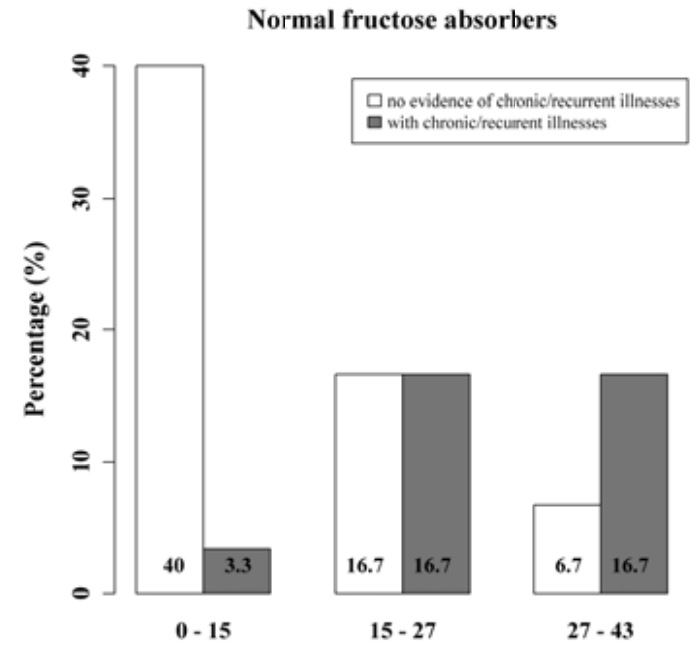

Concentration of mean urinary fructose $(\mathrm{mg} / \mathrm{dl})$

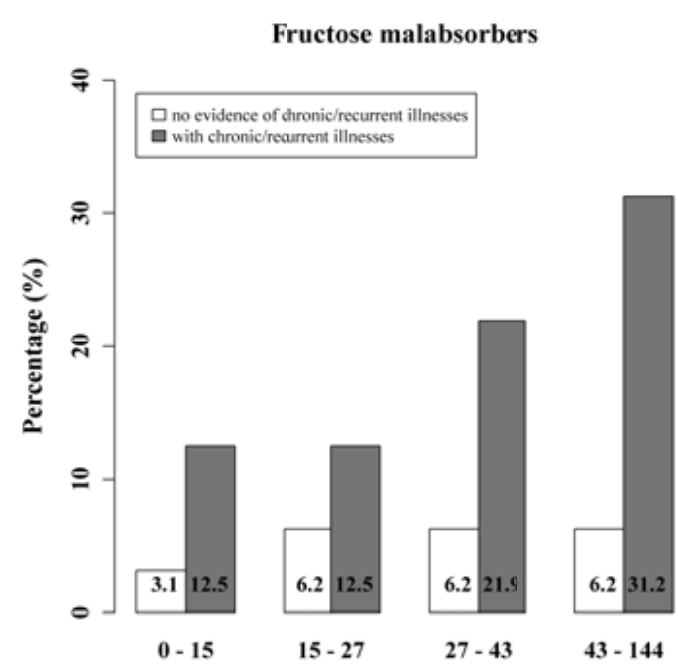

Concentration of mean urinary fructose $(\mathrm{mg} / \mathrm{dl})$

Fig. (4). The frequency of chronic recurrent illnesses in fructose malabsorbers (right) and in normal fructose absorbers (left) increased with the mean urinary fructose level. 


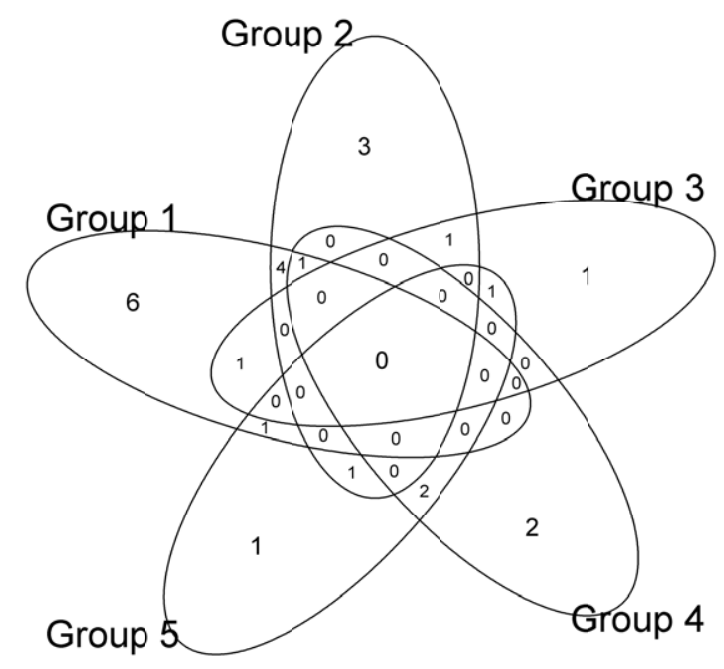

Fig. (5). Twenty-five fructose malabsorbers complained about one or more chronic and recurrent illnesses. Group 1 (Respiratory infections): six patients had respiratory infections. Group 2 (Dyspepsia): three patients had dyspepsia. Group 3 (Heartburn): one patient had heartburn. Group 4 (Recurrent urogenital infections): two patients had recurrent urogenital infections. Group 5 (Inflammation of the skin): one patient had an inflammation of the skin. One patient had a respiratory illness and heartburn. One patient had a respiratory illness and an inflammation of the skin. One patient had a respiratory illness, recurrent urogenital infections and dyspepsia. One patient had dyspepsia and heartburn. One patient had dyspepsia and an inflammation of the skin. One patient had heartburn and an inflammation of the skin. Two patients had recurrent urogenital infections and an inflammation of the skin. Four patients had respiratory illnesses and dyspepsia.

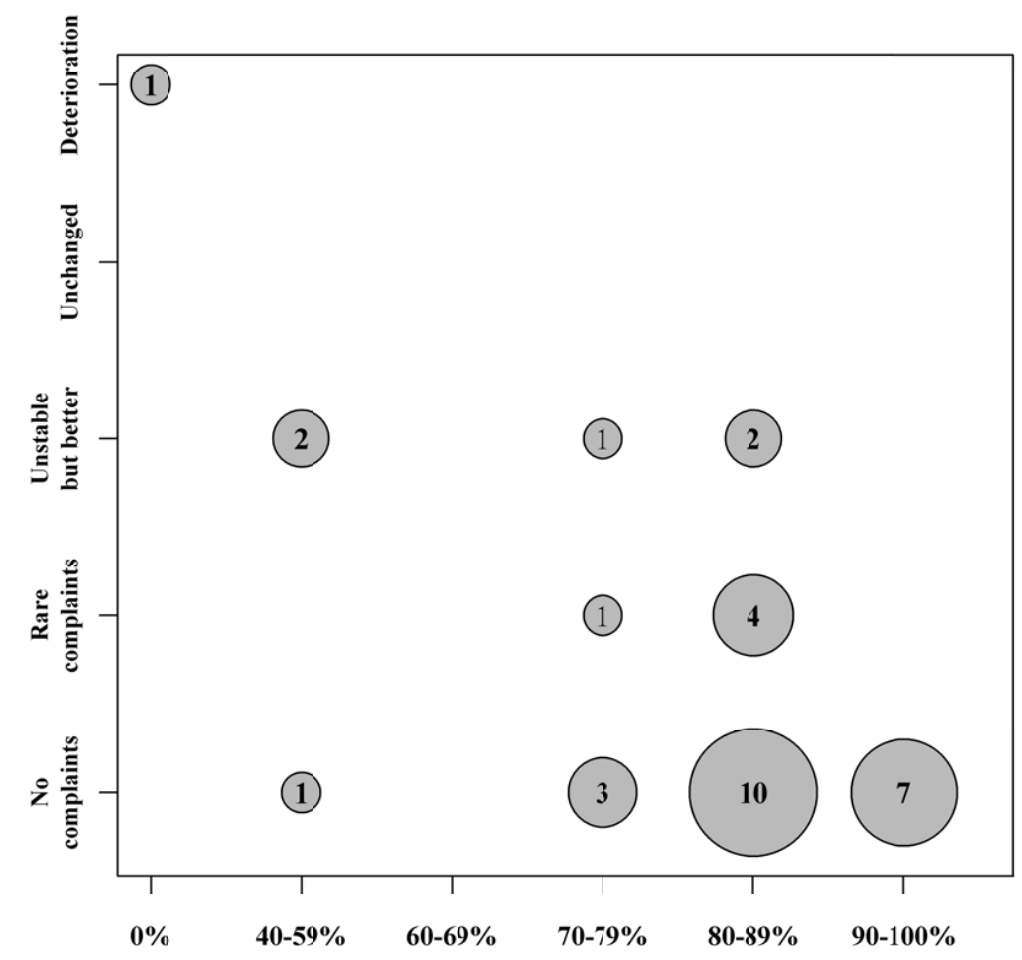

Diet categories

Fig. (6). Improvement of complaints in 21 fructose malabsorbers (four patients did not response to the reevaluation) after adhering to the recommended low fructose diet. Numbers in circles relate to the frequency of individual symptoms in the 6 diet categories. 
typical chronic recurrent diseases observed in fructose malabsorption are shown in Table 1. Infection of the respiratory tract was the most common recurrent disease in fructose malabsorbers (34.2\%), followed by dyspepsia $(26.3 \%)$, inflammations of the skin (15.8\%), recurrent urogenital infections $(13.2 \%)$ and heartburn $(10.5 \%)$. The frequency of chronic and recurrent illnesses increased with the mean urinary fructose concentrations (Fig. 4). Patients frequently showed several complaints simultaneously. Two or three combinations of simultaneous complaints occurred in $48 \%$ of patients with fructose malabsorption and $16.7 \%$ of subjects with normal fructose absorption. Common combinations were chronic sinusitis with dyspepsia, followed by chronic sinusitis with heartburn (Fig. 5). Twenty-one participants of the malabsorption group that suffered from chronic and recurrent diseases were re-examined at a later point (between 2 months up until 3 years after the study). Four of them did not respond and one patient did not stick to the recommended diet. The frequency of chronic and recurrent diseases decreased significantly in all groups after the commencement of the low fructose diet: Twenty-one out of the 32 individual symptoms that were recorded upon admission by the 21 fructose malabsorbers were absent after dietary intervention $(67.8 \%)$. Five symptoms $(16.1 \%)$ improved significantly. Five symptoms (16.1\%) improved, but remained unstable (Fig. 6). Most patients fell in the 80$89 \%$ dietary compliance category (category II) followed by those in the $90-100 \%$ compliance category (category I). The improvement of symptoms correlated strongly with dietary compliance.

\section{DISCUSSION}

The pathophysiology of fructose malabsorption is far from clear. In our study we have observed a much higher urinary excretion of fructose in the so-called "malabsorbers" than in fructose "digesters". The highest concentration of fructose in urine was seen 60 minutes after the $50 \mathrm{~g}$ of fructose intake, which was 30 minutes earlier than the hydrogen peak in the breath. According to current concepts, hydrogen is generated from fructose fermentation by colonic bacteria. From these observations we conclude that the fructose is taken up through a passive process in the small intestine into the circulation and in turn enters the urinary system. This may explain why fructose levels in urine were significantly higher in the group of fructose malabsorption $(\mathrm{p}<0.01)$ with assumed defects in GLUT-5.

The frequency of the chronic and recurrent infections of the upper and the lower respiratory- and urogenital tract and the inflammation of the skin, as well as dyspepsia and heartburn were significantly higher in the fructose malabsorption group $(78.1 \%$ vs. $36.7 \%)$ than the control group. The malabsorbers had a 6.17-times increase risk in chronic and recurrent diseases. The frequency of the chronic complaints in both groups increased with mean urinary fructose concentrations during the fructose tolerance test. It is believed that in fructose malabsorbers fructose is excreted in large quantities in the respiratory tract, stomach, skin and urogenital organs, where microorganisms convert fructose into different organic acids; for example propionic and butyric acid. We speculate that such metabolites contribute to the incidence of inflammation, dyspepsia and heartburn. In GP surgeries patients are often subjected to antibiotic therapy because of recurrent infections, some of them are prescribed several antibiotics over a short period of time. We observed that many of them turn into non-compliant patients with respect to the reuse of antibiotics, or proton pump inhibitor therapy for dyspepsia and heartburn. Various studies have shown that the misuse of antibiotics is not only a major cause of bacterial resistance but also one of the major public health problems worldwide. Also, proton pump inhibitors are overused in Europe, Australia and the USA [24-26]. Since our study demonstrates that a reduced fructosediet effectively remedies chronic and recurrent illnesses of different origins, we propose to use this treatment regimen as a first choice therapy for fructose malabsorbers.

\section{CONFLICT OF INTEREST}

Declared none.

\section{ACKNOWLEDGEMENT}

Declared none.

\section{REFERENCES}

[1] Wasserman D, Hoekstra JH, Tolia V, et al. Molecular analysis of the fructose transporter gene (GLUT5) in isolated fructose malabsorption. J Clin Invest 1996; 98: 2398-402.

[2] Burant CF, Saxena M. Rapid reversible substrate regulation of fructosetransporter expression in rat small intestine and kidney. Am J Physiol 1994; 267: G71-9.

[3] Inukai K, Asano $\mathrm{T}$, Katagiri $\mathrm{H}$, et al. Cloning and increased expression with fructose feeding of rat jejunal GLUT5. Endocrinology 1993; 133: 2009-14.

[4] Kristiansen S, Darakhshan F, Richter EA, Hundal HS. Fructose transport and GLUT-5 protein in human sarcolemmal vesicles. Am J Physiol Endocrinol Metab 1997; 273: E543-8.

[5] Hajduch E, Litherland GJ, Turban S, et al. Insulin regulates the expression of the GLUT5 transporter in L6 skeletal muscle cells. FEBS Lett 2003; 549: 77-82.

[6] Godoy A, Ulloa V, Rodríguez F, et al. Differential subcellular distribution of glucose transporters GLUT1-6 and GLUT9 in human cancer: ultrastructural localization of GLUT1 and GLUT5 in Breast Tumor Tissues. J Cell Physiol 2006; 207: 614-27.

[7] Hajduch E, Darakhshan F, Hundal HS. Fructose uptake in rat adipocytes: GLUT5 expression and the effects of streptozotocininduced diabetes. Diabetologia 1998; 41: 821-8.

[8] Shepherd PR, Gibbs EM, Wesslau C, et al. Human.small intestine facilitative fructose/glucose transporter (GLUT5) is also present in insulin-responsive tissues and brain. Investigation of biochemical characteristics and translocation. Diabetes 1992; 41: 1360-5.

[9] Kayano T, Burant CF, Fukumoto $H$, et al. Human facilitative glucose transporters. Isolation, functional characterization, and gene localization of cDNAs encoding an isoform (GLUT5) expressed in small intestine, kidney, muscle, and adipose tissue and an unusual glucose transporter pseudogene-like sequence (GLUT6). J Biol Chem 1990; 265: 13276-82.

[10] Litherland GJ, Hajduch E, Gould GW, Hundal HS. Fructose transport and metabolism in adipose tissue of Zucker rats: diminished GLUT5 activity during obesity and insulin resistance. Mol Cell Biochem 2004; 261: 23-33.

[11] Mantych GJ, James DE, Devaskar SU. Jejunal/kidney glucose transporter isoform (Glut-5) is expressed in the human blood-brain barrier. Endocrinology 1993; 132: 35-40.

[12] Burant CF, Takeda J, Brot-Laroche E, et al. Fructose transporter in human spermatozoa and small intestine is GLUT5. J Biol Chem 1992; 267: 14523-6.

[13] Funari VA, Herrera VLM, Freeman D, Tolan DR. Genes required for fructose metabolism are expressed in Purkinje cells in the cerebellum. Brain Res Mol Brain Res 2005; 142: 115-22. 
[14] Mate A, de la Hermosa MA, Barfull A, et al. Characterization of D-fructose transport by rat kidney brush-border membrane vesicles: changes in hypertensive rats. Cell Mol Life Sci 2001; 58: 1961-7.

[15] Sasaki A, Yamaguchi H, Horikoshi Y, et al. Expression of glucose transporter 5 by microglia in human gliomas. Neuropathol Appl Neurobiol 2004; 30: 447-55.

[16] Born P. Carbohydrate malabsorption in patients with nonspecific abdominal complaints. World J Gastroenterol 2007; 13: 5687-91.

[17] Park YK, Yetley EA. Intakes and food sources of fructose in the United States. Am J Clin Nutr 1993; 58: 737S-47.

[18] Vos MB, Kimmons JE, Gillespie C, et al. Dietary fructose consumption among US children and adults: the third national health and nutrition examination survey. Medscape J Med 2008; 10: 160 .

[19] Tasevska N, Runswick SA, Welch AA, et al. Urinary sugars biomarker relates better to extrinsic than to intrinsic sugars intake in a metabolic study with volunteers consuming their normal diet. Eur J Clin Nutr 2009; 63: 653-9.
[20] Keller J, Franke A, Storr M, et al. Clinically relevant breath tests in gastroenterological diagnostics-recommendations of the German Society for neurogastroenterology and motility as well as the German Society for digestive and metabolic diseases. Z Gastroenterol 2005; 43: 1071-90.

[21] R Development Core Team. R: a language and environment for statistical computing. R Foundation for Statistical Computing, Vienna, Austria 2008. Available from: http://www.R-project.org

[22] Duller C. Einführung in die nichtparametrische Statistik mit SAS und R. Heidelberg: Physica Verlag 2008.

[23] Hartung J, Elpelt B, Klösener KH. Statistik: lehr- und handbuch der angewandten statistik. München: Oldenbourg Verlag GmbH 1989.

[24] Forgacs I, Loganayagam A. Overprescibing proton pump inhibitors. BMJ 2008; 336(7634): 2-3.

[25] Hungin AP, Rubin GP, O'Flanagan H. Long-term prescribing of proton pump inhibitors in general practice. Br J Gen Pract 1999; 49: 451-3.

[26] MH Katz. Failing the acid test: benefits of proton pump inhibitors may not justify the risks for users. Arch Intern Med 2010; 170: $747-8$.

(C) Sui et al.; Licensee Bentham Open.

This is an open access article licensed under the terms of the Creative Commons Attribution Non-Commercial License (http://creativecommons.org/licenses/ by-nc/3.0/) which permits unrestricted, non-commercial use, distribution and reproduction in any medium, provided the work is properly cited. 